\title{
Cath Raby in conversation with Jen Webb on research higher degree examination administration
}

\section{May 2013, Canberra}

\begin{abstract}
:
This paper is the edited transcript of a conversation between Cath Raby (Research Students Office) and Jen Webb about an administrator's perspective of the process of examining creative arts doctoral theses. Cath has been central to the process since 2000, and has overseen the carriage of examination for creative arts theses in design, architecture, media production, sound production, creative writing and visual art. Cath explains the 'fit' between these theses and those in more conventional forms, and speculates on the value of creative arts doctorates to candidates and the institution.
\end{abstract}

Biographical notes:

Cath Raby is Assistant Manager of the Research Students Office at the University of Canberra.

Jen Webb is director of the Centre for Creative and Cultural Research at the University of Canberra.

Keywords:

Examination - Creative arts - Policy - Procedures 
Cath Raby is the Assistant Manager of the Research Students Office at the University of Canberra (UC). Cath and Jen have worked closely together, for over a decade, on approaches to the management of research students in the faculty. They also worked together to establish the $\mathrm{PhD}$ with creative artefact (which was first offered in 2000), and Cath was instrumental in resolving early questions about approaches to the submission, examination and subsequent storage of creative theses.

They began by recalling early creative arts doctoral candidates who had passed through the UC system, and then reflecting on the rapid increase in numbers enrolled.

Jen: I went through the Trove archive of completed research theses, and a quick search suggested there must be about 600 or so that have completed. Of those, about 450 were creative writing PhDs. That's quite a lot when we consider that the doctorate with creative artefact option only started in the mid-1990s. When we brought in our creative $\mathrm{PhD}$ at $\mathrm{UC}$, we were ninth university in Australia to offer a doctorate in writing. At the moment, about half of the doctoral candidates in the Faculty of Arts and Design are doing creative projects, or working on creative topics.

Cath: It's a pathway, isn't it? But I've also heard, on that topic that, in some countries a professional doctorate is more highly regarded than a $\mathrm{PhD}$.

Jen: Perhaps because it's seen as being practical, so you can do something with it? Whereas the creative $\mathrm{PhD}$ is often seen as a second class $\mathrm{PhD}$, even though the Australian Qualifications Framework counts it as a 'proper' doctorate. Perhaps it's because they often don't provide the research skills that you get from a conventional $\mathrm{PhD}$, but they do provide the high-level professional skills that you don't get from a conventional $\mathrm{PhD}$. And of course, even in conventional $\mathrm{PhDs}$ they are all different - $\mathrm{a}$ science $\mathrm{PhD}$ graduate has a very different experience and knowledge from, say, a communication $\mathrm{PhD}$.

Cath: Just saying 'doctorate' actually doesn't mean very much; it's just a summary.

Jen: Now, I think I know what our rules and procedures are for Creative Arts Doctorates but I'm interested in your perception of them.

Cath: Well we do have rules and we certainly have policies - they are found in the Gold Book. ${ }^{1}$ Part 7 of the Gold Book is what we follow for everything to do with examination, and it has specific procedures for creative theses. But the creative theses are treated more or less the same way as other theses when we're packaging them up to send to the examiners, with guidelines, because at this stage we don't have electronic copies of the submissions.

Jen: Do you have separate guidelines for creative theses?

Cath: Yes. I've actually put my own together, and that goes to all examiners. We also have extra information that goes with a professional doctorate. Having said that, it can all be found in the Gold Book. 
Jen: So it's publicly available as well?

Cath: Yes. The actual document I send, with those little additions - that isn't publicly available. We just use it internally.

Jen: So you put that together as a package?

Cath: Yes. But the actual Gold Book, and all its references - those are all available online.

Jen: I used to know it almost by heart ...

Cath: Unfortunately, I still do; it's sad. [laughs]

So we follow that. And I've had a history of doing this for quite a few years now, from - when was that? - back when I was working in the Division of Communication and Education; and then our students had installations and exhibitions for examination. I was involved with those, and it was a matter of organising examiners to come in and view the installation without the student there. Now, I would say, that's the responsibility of the faculty.

Jen: And did you organise exhibition spaces, meet the examiners, look after them?

Cath: I'm thinking I might have. I think you were the person that had to be there as the ADR; would that be right? Because we couldn't have the supervisor there with the examiner, or we would have breached policy. So it's all very longwinded but yes, we got there in the end.

So yes, we do follow rules and procedures, and those rules and procedures are in our policy, which is openly available.

Jen: Yes, it actually is. One of the things we have done as part of this research project is to go through the websites of the 39 universities to source their policies and work out what the rules are, what degrees they offer in creative arts, what the examination process is, and so on. Often it's not publicly available; or it is, but it's terribly difficult to find it online; or if you do find it, it's either so vague or so detailed that it seems pretty unworkable.

Cath: Well, I think that's how ours was. I mean, if I'd have referred you five or six years ago to the Gold Book you would have said oh, can't you just explain it to me? Part of it was procedure, and part of it was policy ...

Jen: And there were bits of it dotted all over the Gold Book - policy and procedures and guidelines. It was hard to make sense of it.

Cath: Yes; but to me, now, it's fabulous. Though they are going to be reviewing the examination policy: they're looking at that, at the moment.

Jen: What do you think about us including an optional viva voce?

Cath: I think that's probably what will happen: the thesis will go out to the examiners, the reports will come in, then there'll be a viva, and then from that viva you end up with a report. That's my understanding of it. I guess without knowing 
exactly how the process works, as an Admin person, I'm thinking of the timelines involved, and the delays that it may create; but obviously we'll just go with whatever policy dictates. And I guess any change is interesting, isn't it?

Jen: Interesting times. Now, I'm wondering about the proportion of non-traditional research outputs - NTROs - that we see coming through our students' submission. If you're thinking now about doctorates coming through from the whole university, do you have any idea how many of those would be creative ones; one per cent, ten per cent ...?

Cath: It really varies from year to year to be honest. I really couldn't even guess, Jen. I guess the other thing is, you can't always tell easily. For instance, Sandra's was an essay collection and exegesis, bound together like any thesis; but Sally's had that great big suitcase we had to send out, so hers was obviously creative. You can't actually tell by looking, especially with the creative writing ones, because they are often bound as a single object. So if we don't know, we won't necessarily send the guidelines for creative theses, we'll just send the generic ones. But we know how many research students there are in the university, so you can figure it out by knowing how many of your students are doing creative theses. ${ }^{2}$

Jen: As a research administrator, and given your ten years' experience here, do you think the university considers the creative arts as different, as similar, or as special?

Cath: Well, that depends what we are talking about. They are definitely different ... and some are 'special' [laughs]. Thinking back to when we were organised as divisions, the creative students were treated differently as far as administration was concerned because they needed different things; they needed an installation, they needed the examiners to be at the installation, that sort of thing. Nowadays, because we're centralised and the faculties are doing that side of it, from where I sit in our office as an administrative processor, no, they're not different. They have the same timeframes; if they have an installation, it's the faculty's problem or the supervisor's. As far as I'm concerned, you get it in, and I'll send it out and chase up the examiners and so on.

Jen: In some ways that's wonderful because it means that creative research has been integrated into the research culture; but in some ways it's a bit sad because we think of ourselves as being special, and we're not. [laughs]

Cath: I quite like being over here in Student Administration; it makes sense that we're here, because there are so many crossovers. And when there's an issue, we can physically go to someone else and say, hang on a minute this one's left-of-centre. And that's good, because it's about trying to help these guys get through it all.

Jen: I've been talking to people from outside UC who are in research management positions, and asking them about how they manage research students, and they pretty much all say that you must work with them early on, to get them to understand that this is their job for the next three or four years, and that they should be working at that job for seven and a half hours a day, five days a week. 
Cath: That's actually a good way to look at it, because so many of them seem to think it's a bit of a hobby.

Jen: Something you tack on the side to do when you have a bit of time; but you never have time, there's always something else.

Cath: And there's always something that's going to hit you left-of-field, so if you're not that driven ... Perhaps that's because they've got the wrong frame of mind, or perhaps we have the wrong timeframe.

Jen: I do think the new research training system is going to help, with having students do coursework in their first six months, and making sure that they have really have a clear and well designed research project

Cath: Yes - as long as the faculties make sure that they are honest about it; and I think people are starting to get the message. It's more work for everyone if students aren't properly trained. I mean, you're looking at another 12 months of enrolment if their result is 'revised: resubmit after examination', let alone all the delegation at the moment. The DVC-R and the ADR and the supervisor all have to put quite a lot of time into problems, and then in Admin we have to do all the timelines and send everything out again, and then it all has to come back, and then we have to collate it again ...

Jen: So you actually do all the management of that?

Cath: Yes, I used to do that as part of the examination process. At one point we had so many coming through, I thought I just wouldn't cope with it it, couldn't keep a handle on it. Right now I'm just finishing off, and should probably sign off on seven theses; so at the moment I'm chasing examiners.

There's a new report that is being developed for me to get the information I need. I've got the developers to build in all the information that you would expect to have on a spreadsheet: the date that it was actually sent to the examiner, then is how many weeks it's been out. The top one is 23 weeks, but often it's 17 , or 13 weeks ...

Jen: As much as that? I thought we were all getting better at timely examinations.

Cath: No.

So then I have to go and nag everyone. No wonder I'm exhausted when I get home, really. [laughs] But I have just done a big nag, and now I've five reports sitting there that I have to process today. Oh dear. [laughs]

Jen: So what's the process at the point of examination?

Cath: We make an appointment with the student, and then I give them a signed declaration that they've actually submitted on that date, in case they need it to provide to someone. And on the back of that I give them the flowchart of the examination process, so they know when they should expect the reports to come in. 
Then I send them an email confirming that they've submitted, and both copies - or three copies - have gone out. So my biggest headache at the moment is people coming back in mid-March, and saying you said mid-March, where is it?

Jen: Thinking about when you deal with examiners: do you think that the examiners of creative theses are different from examiners of more conventional doctorates?

Cath: I guess really I haven't thought about it. I do deal with every examiner because I'm the point of contact. It's usually by email; occasionally I'll get a phone call about something they're unsure of, but it's usually pretty respectful. I'm very mindful of my position in representing the university for them, so I tread carefully. And I don't know that I could say, oh, well, that one's a wacko because they're a creative arts person, I mean ...

Jen: We were wondering if there might be a difference because in the creative arts there is always the likelihood that you'll have an artist or a director, say, as one of the examiners, rather than a conventional academic, so we wondered if they seem to be a different cohort. Are they less familiar with the expectations or with the process, do you think?

Cath: I think that's a hard one to answer because basically all our doctorates are pretty much processed in the same way; it would only be something slightly left-ofcentre that would make me think, oh, that's creative arts, okay; but I haven't had to do more explaining or anything, I think because we've covered that with our guidelines.

Jen: And they are comprehensive and clear?

Cath: Yes. The first lot of guidelines I put together, I think, in about 2009. At that point we went through all our processes, and checked them against benchmarks, so I think from that we've tightened things up and tried to cover all that bases. I mean, having said that I'm very conscious of tweaking things here and there within policy, to make it more informative for examiners, to help them.

Jen: I think one of the really interesting things about your job is that you really do know the policy, and you often write it or contribute to it.

Cath: Oh, definitely. We're always consulted about any changes that are happening, and I've met with the policy officer for hours, talking about how's this going to work? How's that going to work? I try to be really objective. I don't mind if they turn around tomorrow and tell me I have to do it totally differently: I'll do it differently. I'm not here to put up brick walls up; I'm here to make sure that the process is streamlined and working for everybody.

Jen: I'm interested, given that you are someone who is so involved in policy, about the principles you work from when you're dealing with policy? Is it about making it more effective? Is it about achieving better outcomes? 
Cath: Well, I guess our policy is driven by the university's requirements and what, at the end of the day, the university wants to get out of it. Everyone's batting for the same team, as far as I'm concerned, and that is to get the students across the line.

But having said that there's a couple of hoops that you actually have to jump through, and some students think they don't need to. I mean ... unfortunately a lot of people come into a doctoral degree thinking that they're just going to write a report, or for creative students, that they just need to write a book. But they have to do research, and they have to include referencing and all sorts of things.

So as far as that goes; I guess in the Admin restructure, in - was it 2007? Yes - we inherited the Gold Book, and then we had the working party which nutted through how to fix things; and now we have the GRO [Graduate Research Office] and they more or less do the policy. They consult with us because we're the hands-on people, asking, but how is this going to work?

Jen: So the GRO is looking at governance legislation and the Australian Qualifications Framework, and so on, to make sure that we're compliant; and then you see whether that policy is actually workable or not?

Cath: That's right. We work differently.

Jen: Now, you are the one who actually receives all the examiners' reports. Do you think the examiners actually read and follow the guidelines?

Cath: Some really do, and then with some people you just go, okay. You just have to go with what you're given. But some people, for the pittance that we pay them, are unbelievably thorough, incredibly thorough. They'll put in 13, 14 pages of typing and it's only a B result. And I think whoa, should it be a B then?

Jen: So they really engage actively?

Cath: Yes. And some really want to know more. Occasionally I get an examiner come back to me saying I'm a bit confused about this, this and this; I just send that on to the supervisor because I'm the liaison link between them.

Jen: So that is, if the query is about the content of thesis it's the supervisor's responsibility, and if it's about process, you deal with that?

Cath: Yes. If it's about content, I'll take it to the supervisor and say well, what do we do here, can you explain this? And then I give the feedback to the examiner. But by and large there's a mixture of content and process questions.

Having said that, I remember when one of our creative students wasn't marked very favourably. All his examiners gave him a D [revise and resubmit], but one of the examiners came back to me because they were concerned about the student, and asked if they could get in contact with him. That's fine by the policy, as long as I've got permission. So I did all that background stuff, got them together and they gave him extra feedback. That was so admirable; he was so thankful for that feedback. It's what got him through, instead of just falling in a hole - which you'd want to do. So that 
was a really positive outcome from people who were obviously very thorough, and took the whole thing really seriously, and treated the examination in a formative way.

And a lot of people do that, Jen. I don't read every single report but I sort of scan over the front of them, and some of them have a covering letter to me saying this is just absolutely wonderful and they should be commended. I'll cover everything up as I do, hide the examiners' names, because I have to, but I'll send that through as well as the reports so that they get that accolade.

But we have had a couple of reports where the examiner has just absolutely slammed the thesis, slammed the supervisor, can't believe this was actually sent out. Policy allows students to submit, regardless of what the supervisory panel may or may not say, even if they really shouldn't have submitted. But now the policy is that if someone is going to submit without the support of their supervisor, they have to ask the permission of the Associate Dean of Research. So it has to be approved, even if the supervisor or the ADR says well, I don't think it's a good idea. And most students who have submitted without permission - or without support, I should say - have been hammered by the examiners.

Jen: So the system actually works?

Cath: I think so; I think it does. And I think we're at a stage where we've tightened it up. As I said they're reviewing the policy and procedures now, and it's nice to be part of this instead of just running, guns blazing, on a crazy treadmill. We're actually stopping now and reflecting on what we've got, and whether it works. We're tightening things up so that it can be even better.

Jen: So the policy and the procedures really do support a successful completion?

Cath: Yes. I'm really pleased with where we are now.

Jen: It can't be easy when you think that we do everything from strange design projects to work on lizards to education research ...

Cath: Well I guess, from where I'm sitting, because we're a processing point, it doesn't actually matter that much what the content is. As long as it fits the policy. For example, we had a thesis to send out and it was huge: two volumes, and physically huge. One examiner said well, no, this is way over what it should be - clearly he'd read the policy - it's way over what it should be and I don't have time to examine this. So the supervisor went back to the student and said, how long is your thesis; I'm thinking, I would have thought you'd know that but ... The student came back and said it was totally within the 100,000 words maximum. But meanwhile back at the ranch, the examiner said, no, I'm not doing it.

Jen: I've had a few really big ones to examine, but usually that's because they have long appendices, and I'm not actually prepared to examine appendices. I'll flick through them to see if they make sense, but I'm not going to comment on them. 
Cath: And they're not actually included in the word count.

Jen: It's just a back-up for the student, to help them be sure of what they're doing. And later, if it's a good thesis and somebody else wants to use it in their research, they've got all that data there, so it's much more useful to them. But I don't think it's part of the examining process.

Now, thinking about the sorts of results we're seeing for doctoral examination: do you have any sense of whether the success rates for creative theses are the same as the rest, or higher, or lower?

Cath: No, I don't think so. For the ones we've had where the outcome is revise and resubmit, that really happens across the board. You couldn't have said, oh, look at that faculty, there all the problems are. We had a group of those last year.

Jen: What happened?

Cath: I don't know; probably a couple of things. It could have been a cohort that really shouldn't have come through. It could have been that they were inappropriate examiners - though we've tightened up on the examiners we use; it could have been inappropriate supervision. I mean, how do you know?

But we've increased our student numbers incredibly, and that's the other driver for me to get these reports and these mechanisms in place. I mean, I don't want to be the only person who knows it all. Yes, I have corporate knowledge, but I work as part of a team, and I want to make sure that everything's transparent, so that if I'm not there someone can just run a report, so that we all know what's going on. We're getting there.

Jen: Still on that question of outcomes; I think this would have to go back to when you were still in the Division, and working more closely with supervisors - did you have any sense of whether students and supervisors of creative art doctorates wanted or expected the same sort of outcomes as those in other disciplines?

Cath: Well, you would hope so. [laughs] Are we talking here about the actual result?

Jen: Partly the actual result, but also, where do they want to go with it? Are they aiming at an academic career? Do they want to become a better writer?

Cath: Or is it a hobby?

Jen: Or is a hobby? Do you think there's a hobby-sense in some of the other disciplines, or is that more evident in the art forms?

Cath: I'm probably being a bit unfair; I guess some people out there think that they're just going to do a $\mathrm{PhD}$ because they're retired, and they've always been clever, and they think that it's the be-all and end-all, and I've got time on my hands now so I think I'll do it. Our $\mathrm{PhD}$ candidates are quite old; the average age would be over 40. So, without being any expert on this, I sometimes think, well, are you an emerging academic? Probably not, so what's the driver? Is it work? Probably not. Maybe it's just curiosity. For some of them, perhaps it's prestige. And in Canberra 
where there are so many PhDs, maybe if you're a senior person and you don't have a $\mathrm{PhD}$, you feel like maybe you should have one. [laughs]

Actually, we had one student who was 70-something, and doing a PhD. And in my 12 years, it's the first time that we've actually ended up with Masters as the outcome. We've always had the option of a downgrade, but I hadn't seen it before.

In the last couple of years, though, we've had a few outside-the-box cases. It's hard to know if it's because we're taking more students in; or if it's the result of the she'll be right, mate attitude; or for some of them, they've just been around for too long, and they're never going to listen to anyone. In one case, I think the supervisory panel had changed a bit, but in the end I think it was that she'll be right mate culture. I asked the academic who'd signed off to say the thesis was ready to go to the examiners, and they said, oh, no, I just signed off as an Admin person, I actually didn't have anything to do with it ... (It wasn't someone from your faculty!) But I'm just saying generally out there, from an Admin point of view, there's some poor practice.

I get questions every day from supervisors asking how things work. I always send them the policy link because I'm trying to train people to have a look. Supervisors need to have training, and retraining; but unfortunately like everything, the people who turn up for the training are not the ones that necessarily need to be there.

I think generally speaking supervision is not that good, and that's part of our problem. We did have the culture where we'd say, look, let's just get it through because the meeting's on this day and we have to have a panel so let's just put these names down. But there's much more rigour now. And people are starting to understand that they've got to be accountable, and that's good.

Jen: I know you've done some benchmarking; so from your perspective, what are our policies and procedures like in terms of their breadth, scope and rigour compared with our comparator universities? Are we doing okay?

Cath: That's probably a question for [my colleague]. I mean, at the end of the day, I just do what the policy says. And in the benchmarking I do the practical bits - like, if we're going to do that, how are we going to do this? How are we going to manage this? And what's the timeframe? I think it works well. It's come a long way in ten years, and that's what's exciting.

Before, when we just sort of muddled through, it was ... well. And people did get really upset about one thing or another. But I guess finally it is getting the students out the door: it's about that human journey, and helping them. I think I'm very fortunate that I'm at the end of the journey, because it is an end, and they can see an end and together we get to the end.

I think it's very rewarding from where I'm sitting, being involved with the changes and embracing the changes and trying to build our whole research culture, and improve our profile; and dealing with the people. I just love being there to help the people where I can, so it's good, life's good. 


\section{Endnotes}

1. University of Canberra 2012 'Higher degrees by research: policy and procedures (The Gold Book)', at http://www.canberra.edu.au/research-students/goldbook. Part 7 is titled Examination of Higher Degree by Research Theses Policy, and includes sections for Masters by Research Thesis, PhD by Publication, and PhD thesis that incorporate creative production. For the Masters and $\mathrm{PhD}$ thesis, the creative component must be prepared during the candidature; in all three cases, the exegetical and creative components must operate in a symbiotic relationship (or may be fully integrated); and at doctoral level the work submitted for examination must make a distinct and significant contribution to knowledge, or understanding of the area with which it deals.

2. A back-of-napkin calculation indicated that some 7 per cent of research students at the University of Canberra, and nearly 70 per cent in the Faculty of Arts and Design, are completing creative research degrees. 